\title{
Estimation of Seasonal and Annual Albedo of the Earth's Atmosphere over Kano, Nigeria
}

\author{
Audu, M. O. ${ }^{1}$, Isikwue, B. C. ${ }^{2}$, Eweh, J. E. ${ }^{3}$ \\ (Physics, University of Agriculture, Nigeria)
}

\begin{abstract}
This research investigated the seasonal and annual albedo of the Earth's atmosphere over kano due to its location close to Sahara Desert which greatly influence its atmospheric and climatic conditions. The data used for this study were obtained from the International Institute for Tropical Agriculture, Ibadan. The data span for 34 years (1977-2010). The model for shortwave solar energy balance at the edge of the Earth's atmosphere was adopted in this work. The results show that, seasonally, the maximum albedo of 0.58 was obtained in August (the peak of cloud activity) while the minimum albedo of 0.41 was recorded in November (the onset of dry season) when it was relatively cloudless and dustless. Annually, the maximum (0.60) and minimum (0.37) albedo were obtained in 2002 and 1995 respectively. The results also show that the relationship between clearness index, sunshine hour, air temperature and global solar radiation with albedo depict direct opposite. The albedo simulated was compared with the results of other places having almost latitudinal location and co-ordinates similar to that of Kano.
\end{abstract}

Keywords: albedo, clearness index, Earth's atmosphere, Kano.

\section{Introduction}

The Sun is the dominant direct energy source of the terrestrial ecosystem as it affects all physical, chemical and biological processes [1]. Among the renewable energy resources, only solar energy has the greatest potentiality, availability and is free from environmental hazard [2]. The solar radiation reaching the Earth's surface depends upon climatic condition of the location, hence, the study of what happens to sunlight as it passes through the atmosphere is crucial to many aspects of science and general knowledge.

Over the years, the amount of solar radiation reaching the Earth's surface has being modified through reflection, scattering and absorption in the atmosphere. The fraction of the incident solar radiation that is reflected and scattered back into space is called albedo. Albedo or reflection co-efficient is also known as reflectance or reflectivity of a surface. The average overall albedo of the Earth, its planetary albedo, is about 0.3 . This fraction of incoming radiation is reflected back into space. The other 0.7 part of the incoming solar radiation is absorbed by our planet [3].

The Earth's albedo affects the amount of Sun-light the planet absorbs. It plays a major role in the energy balance of the Earth's surface, as it defines the rate of the absorbed portion of the incident solar radiation. Hence, it has a direct effect on Earth's energy budget and, therefore, global temperatures. If the Earth receives more energy from the Sun than it sends back to space, the Earth gets warmer. On the other hand, if the Earth reflects more of the Sun's energy than it absorbs, the Earth gets colder.

Some research works on the albedo of the Earth's atmosphere for different locations have been carried out [3], [4], [5]. Most of the estimated short-wave broadband albedo are from satellite data and are often corrected for geometric, atmospheric, spectral, topographic, and anisotropic effects in order to obtain accurate results [6]; [7]. However, none of these works has estimated albedo over the atmosphere of Kano, Nigeria. Hence, this work hopes to investigate the atmospheric condition of Kano which is mostly affected by the continental air masses from the Sahara Desert.

Kano city is located on latitude $12.0^{\circ} \mathrm{N}$ and longitude $8.3^{\circ} \mathrm{E}$ within the semi-arid Sudan savannah zone of West Africa about 840 kilometers from the edge of the Sahara desert [8]. The atmospheric condition over Kano is greatly influenced by the Sahara Desert. Kano has a mean height of about $472.45 \mathrm{~m}$ above sea level. It is the largest state of the Nigerian Federation having a land mass of about $20,131 \mathrm{~km}^{2}$ with a population of 9,383,682 according to the 2006 census. Agriculture is one of the most important pillars of the State's economy with about $75 \%$ of the total working population engaged directly or indirectly in this activity. It is also the second largest industrial center in Nigeria and the largest in the Northern Nigeria [8].

Kano has two seasonal periods, which consist of four to five months of wet season (May - September) and a long dry season lasting from October to April. The temperature of Kano usually ranges between a maximum of $33^{\circ} \mathrm{C}$ and a minimum of $15.8^{\circ} \mathrm{C}$; although sometimes during the harmattan it falls down to as low as $10^{\circ} \mathrm{C}$. The average rainfall is between $63.3 \mathrm{~mm}+48.2 \mathrm{~mm}$ in May and $133.4 \mathrm{~mm}+59 \mathrm{~mm}$ in August, the wettest month [8]. 


\section{Sources Of Data And Method Of Analysis}

The monthly mean daily global solar radiation, sunshine hour and air temperature data used in this research were obtained from the International Institute for Tropical Agriculture, Ibadan, Nigeria. The data span for 34 years (1977-2010).

Short wave solar energy balancing at the edge of the atmosphere can be computed using the relation given by [9] as:

$$
\frac{H_{m}}{H_{o}}+\frac{H_{a}}{H_{o}}+\frac{H_{r}}{H_{o}}=1
$$

Where $H_{m}$ is the global solar radiation, $H_{o}$ is the extraterrestrial radiation incident on the surface of the Earth at the edge of the Earth's atmosphere, $H_{a}$ is the absorbed solar radiation, $H_{r}$ is short wave reflected radiation, $\frac{H_{m}}{H_{o}}$ is the ratio of the global to the extraterrestrial radiation called clearness index and $\frac{H_{a}}{H_{o}}$ is the fraction absorbed called the absorption coefficient or absorptance.

$\frac{H_{a}}{H_{o}}$ has been found to be very small compared to the other ratios, hence negligible i.e. $\frac{H_{a}}{H_{o}}<<1$, [9]. Equation (1) then becomes:

$\frac{H_{m}}{H_{o}}+\frac{H_{r}}{H_{o}} \approx 1$

Therefore, the reflectivity or albedo can be estimated using:

$$
\frac{H_{r}}{H_{o}}=1-\frac{H_{m}}{H_{o}}
$$

The extraterrestrial radiation, $\mathrm{H}_{\mathrm{o}}$ is the solar radiation received at the top of the Earth's atmosphere from the Sun on a horizontal surface and it is considered as the incident solar radiation. The monthly mean daily extraterrestrial radiation, $\mathrm{H}_{\mathrm{o}}$ on a horizontal surface was computed from the equation of Duffie and Beckman (1991)[10] given as:

$H_{o}=\frac{24}{\pi} G_{s c}\left\{\left[1+0.0033\left(\frac{360 J}{365}\right)\right]\left[\left(\frac{\pi}{180} W_{s} \sin \emptyset \sin \delta+\cos \emptyset \cos \delta \cos W_{s}\right)\right]\right\}$

where $\mathrm{W}_{\mathrm{s}}$ is the sunrise, sunset hour angle given by [11] as:

$\mathrm{W}_{\mathrm{s}}=\cos ^{-1}(-\tan \emptyset \tan \delta)$

$\emptyset$ and $\delta$ are the latitude and declination angles respectively. The value of declination was computed from the equation of [12] as:

$\delta=23.45\left[360\left(\frac{J+284}{365}\right)\right]$

where $J$ is the day number of the year (known as the Julian day). $G_{s c}$ is the solar constant in $\mathrm{MJm}^{-2} \mathrm{day}^{-1}$. The value of $\mathrm{G}_{\mathrm{sc}}$ used in this work was $4.921 \mathrm{MJm}^{-2} \mathrm{day}^{-1}$.

By substituting the value of $\mathrm{G}_{\mathrm{sc}}$ and equations (5) and (6) into equation (4), the monthly mean daily extraterrestrial radiation, $\mathrm{H}_{\mathrm{o}}$ on a horizontal surface was computed. Subsequently, this was used as one of the input data in computing the reflection co-efficient using equation (3). The annual mean global solar radiation, sunshine hour, air temperature and albedo were computed from the monthly means.

\section{Results}

The comparison between monthly mean clearness index and reflection co-efficient is presented in Figure 1a. The trend in variation of monthly mean air temperature with reflection co-efficient, variation of monthly mean sunshine hour with reflection co-efficient and variation of monthly mean global solar radiation with reflection co-efficient are shown in Figures $2 \mathrm{a}-4 \mathrm{~b}$. The variations of annual means albedo with clearness index, air temperature, sunshine hour and global solar radiation are shown in Figs. 1b- $4 \mathrm{~b}$ respectively. 


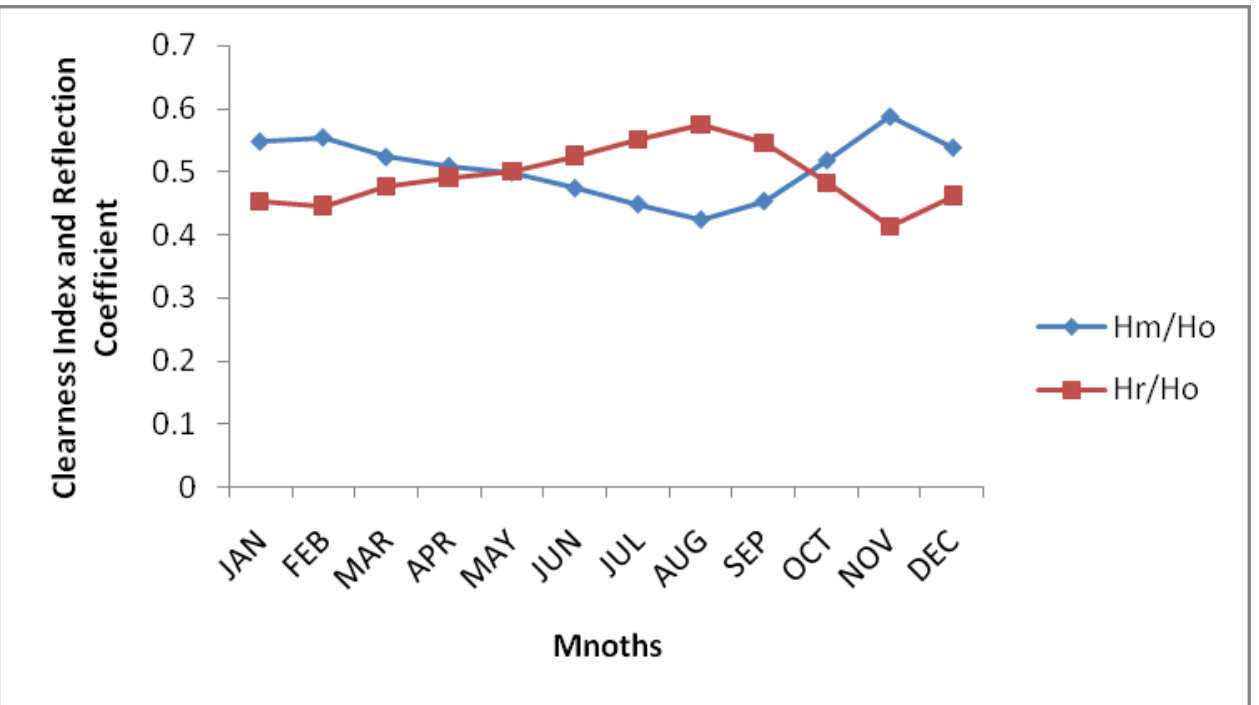

Figure 1a : Comparison between monthly mean clearness index and reflection co-efficient.

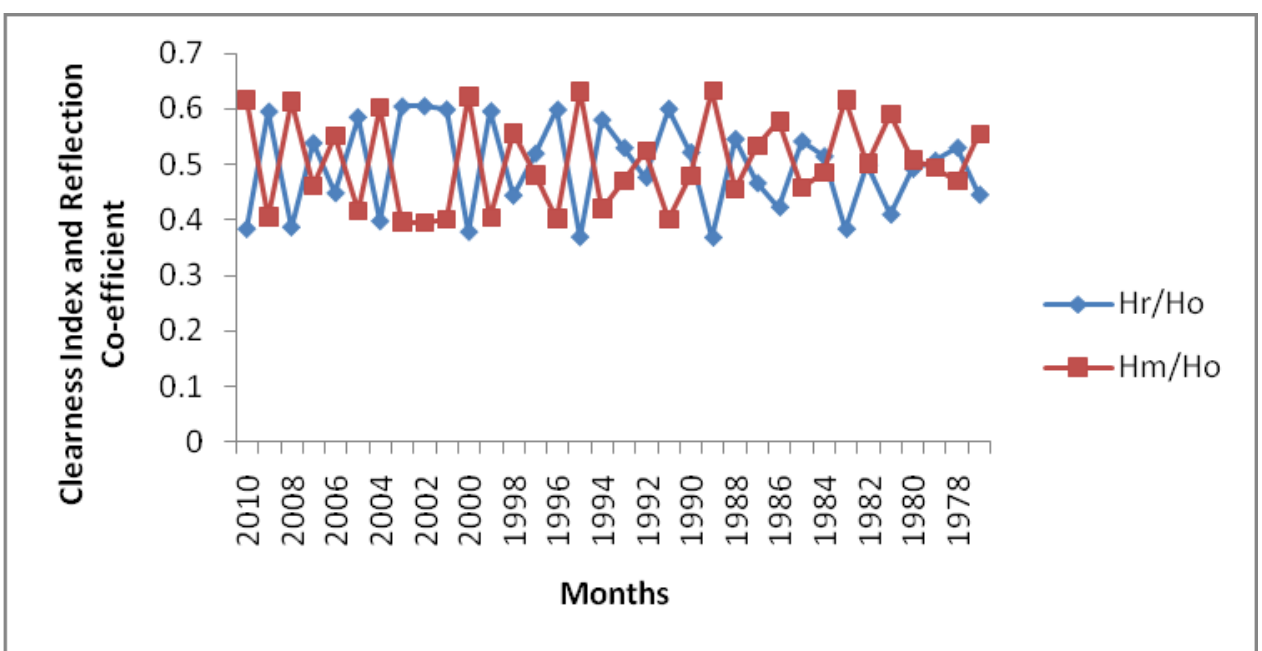

Figure 1b : comparison between annual mean clearness index and reflection co-efficient.

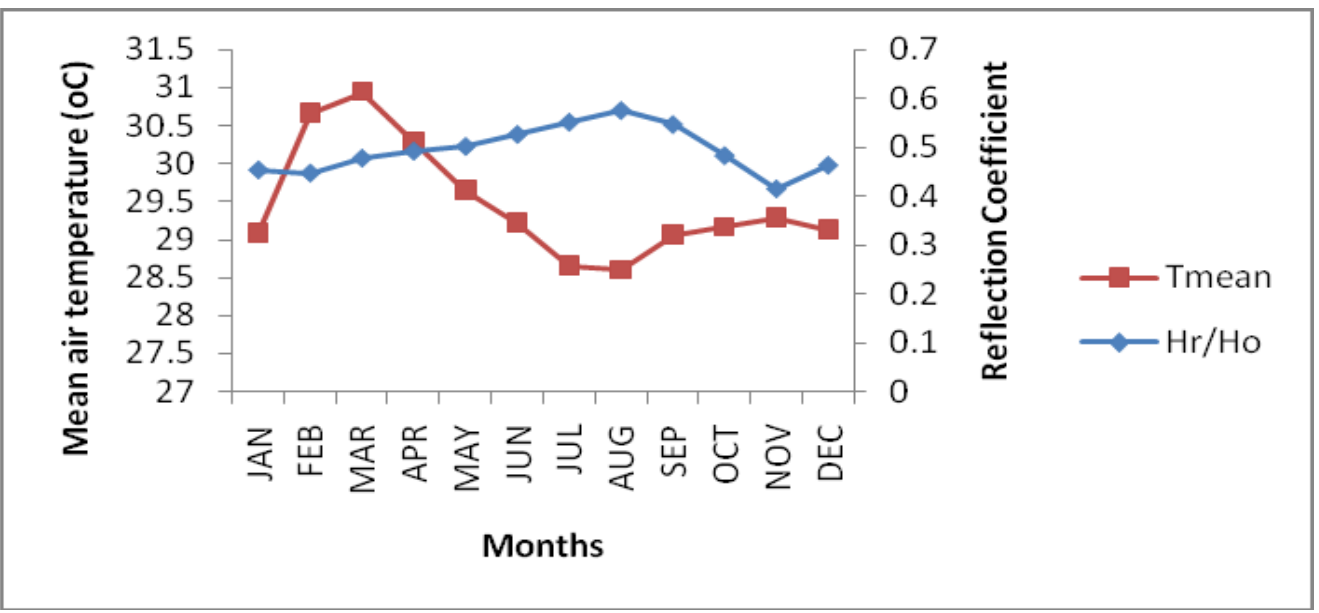

Figure 2a: The trend in variation of monthly mean air temperature with reflection co-efficient 


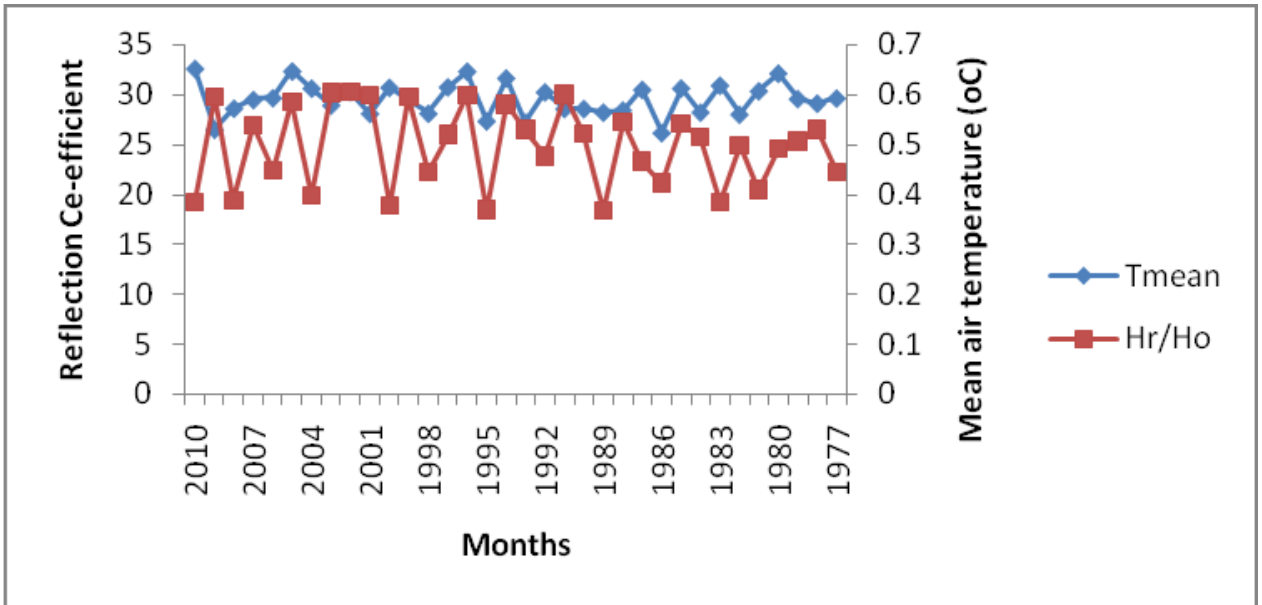

Figure 2b: Variation of annual mean air temperature with reflection co-efficient

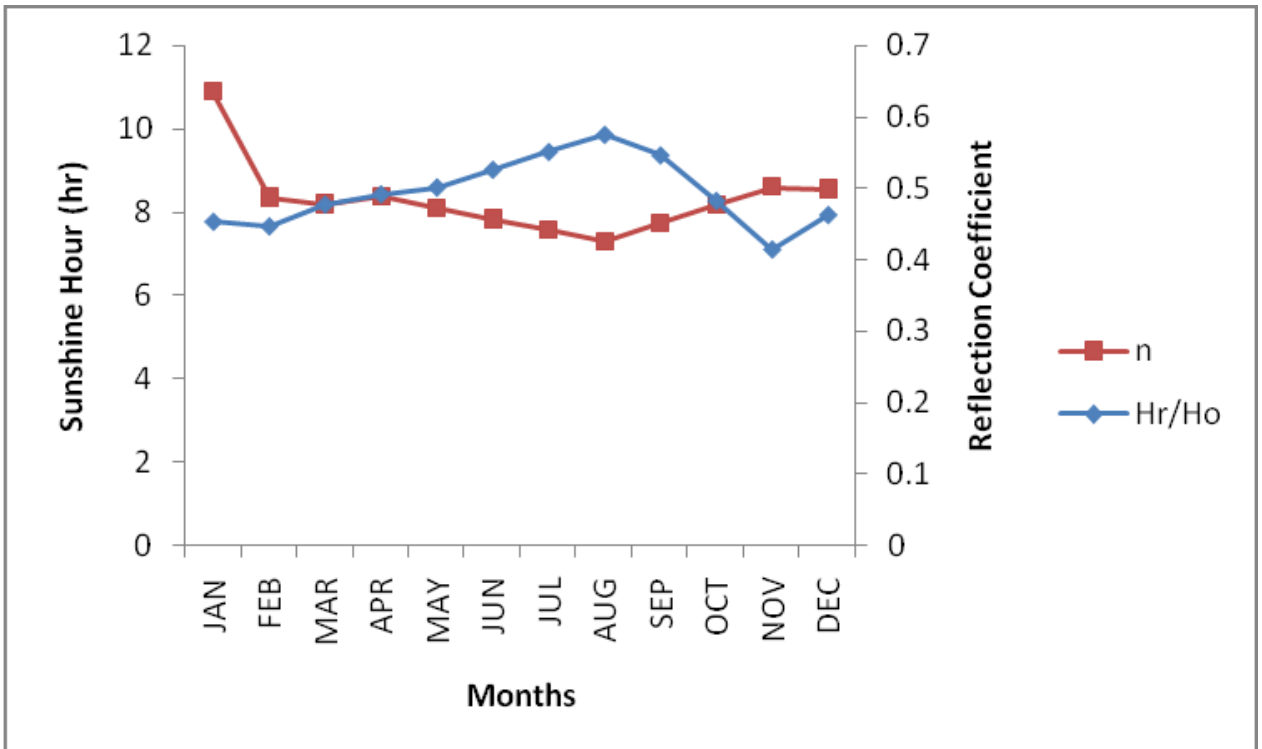

Figure 3a: variation of monthly mean sunshine hour with reflection co-efficient

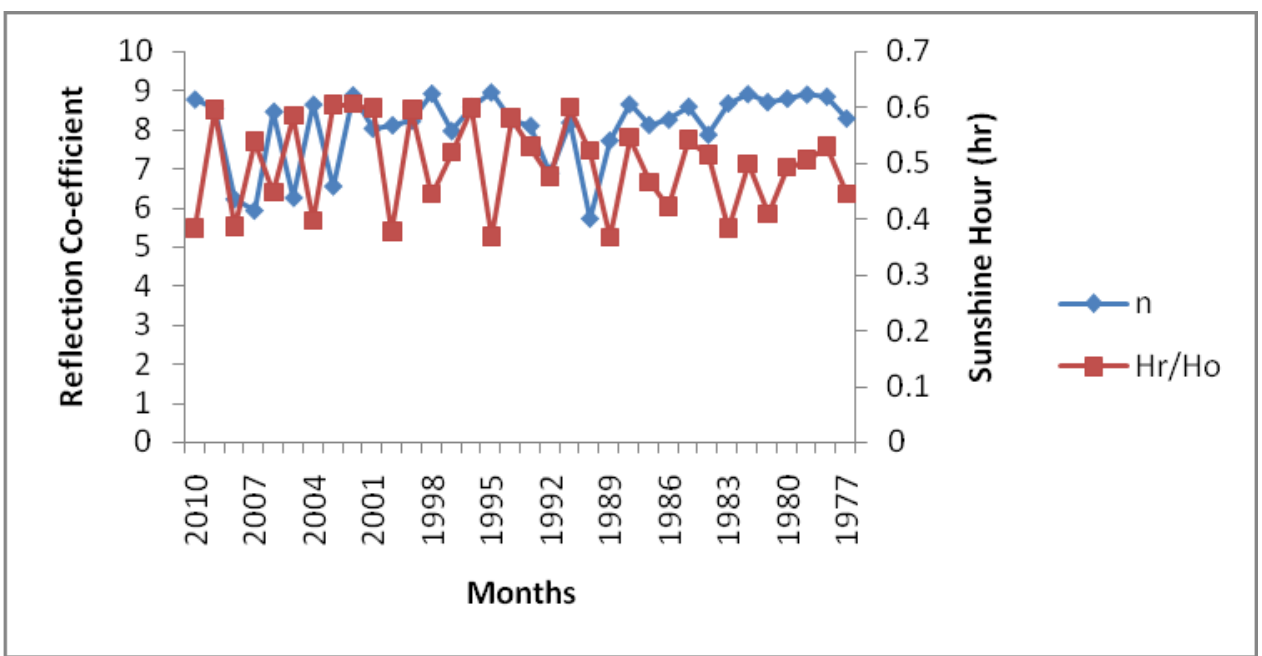

Figure 3b: variation of annual mean sunshine hour with reflection co-efficient 


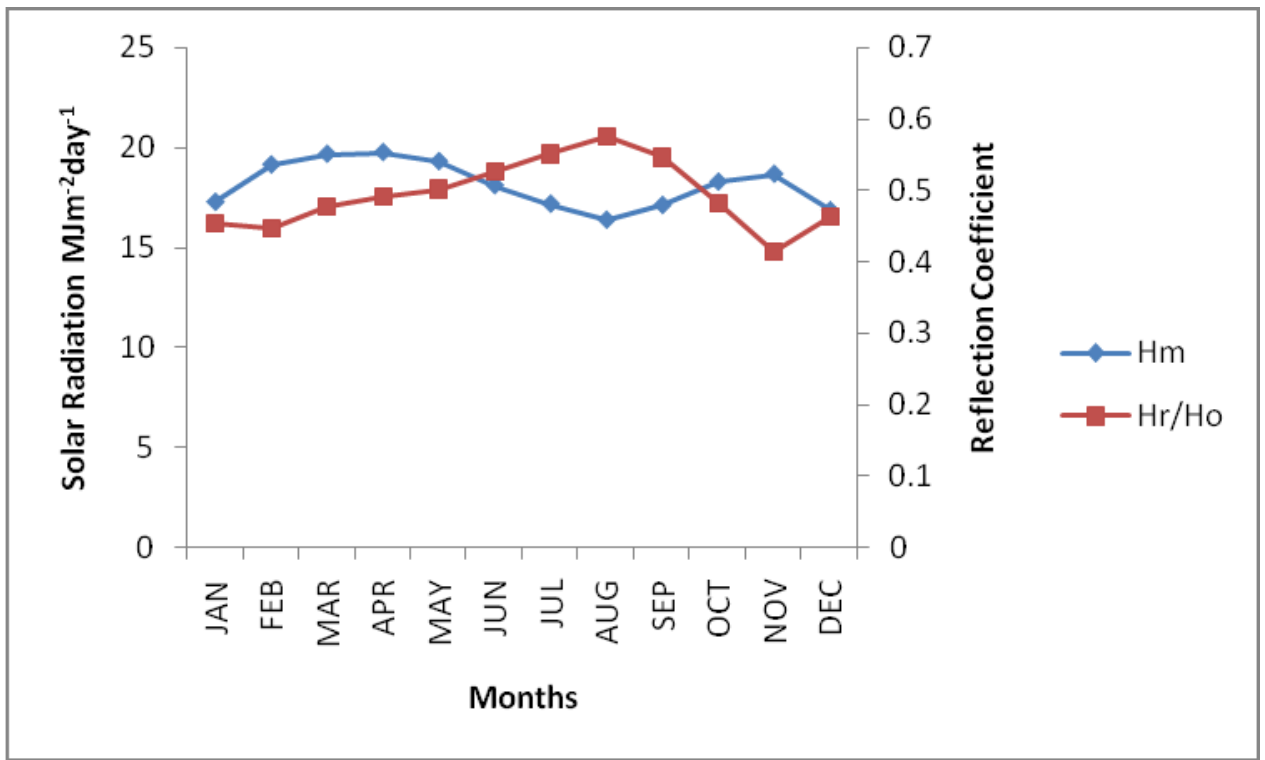

Figure 4a: Variation of monthly mean annual global solar radiation with reflection co-efficient

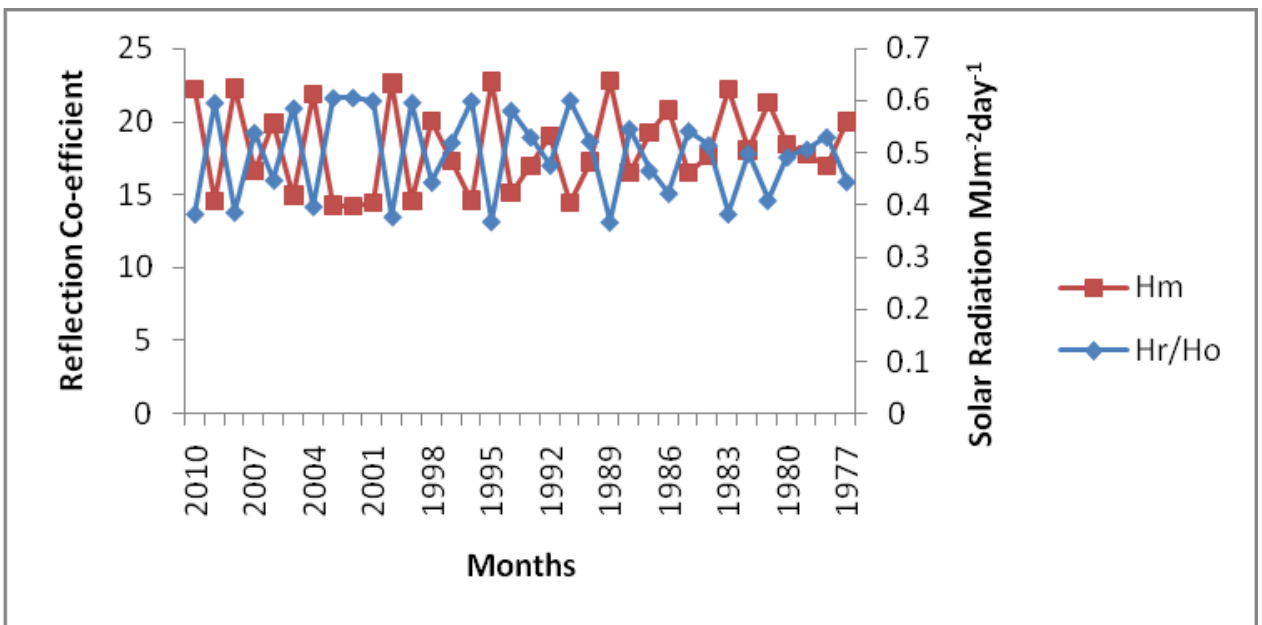

Figure 4b: Variation of annual mean annual global solar radiation with reflection co-efficient

\section{Discussion}

It could be observed from Fig. 1a that the highest reflection coefficient $\left(\mathrm{H}_{\mathrm{m}} / \mathrm{H}_{\mathrm{o}}\right)$ of 0.58 was observed in August, the wettest month; this corresponds to the lowest clearness index $\left(\mathrm{H}_{\mathrm{m}} / \mathrm{H}_{\mathrm{o}}\right)$ of 0.425 . This was probably due to the rain bearing clouds which pervaded the sky in the rainy season. On the other hand, during dry season, the highest value (0.587) of $\mathrm{H}_{\mathrm{m}} / \mathrm{H}_{\mathrm{o}}$ was observed in November which corresponds to the lowest value $(0.41)$ of $\mathrm{H}_{\mathrm{r}} / \mathrm{H}_{0}$. This may be due to the fact that the sky was cloudless and free from harmattan dust.

From Fig. 2, it could be observed that surface air temperature was high during dry season with the highest value $\left(30.935^{\circ} \mathrm{C}\right)$ in March while the lowest temperature $\left(28.600^{\circ} \mathrm{C}\right)$ occurred during rainy season in August when the sky is cloudy. This corresponds to the highest reflection coefficient. It implies that Earth's surface temperature decreases as the albedo increases because most of the solar radiations are reflected back into space. This inverse variation of Earth's surface temperature with albedo was observed by [3]. The highest $\left(32.52^{\circ} \mathrm{C}\right)$ and lowest $\left(26.18^{\circ} \mathrm{C}\right)$ annual mean air temperature was observed in 2010 and 1986 respectively.

From Fig. 3a, it could be observed that during rainy season when the sky is cloudy, the lowest sunshine hour ( $7.305 \mathrm{hrs}$ ) was observed in August and this corresponds to the highest value $(0.575)$ of $\mathrm{H}_{\mathrm{r}} / \mathrm{H}_{\mathrm{o}}$. On the other hand, the highest sunshine hour (10.88 hrs) was observed during dry season in January when the sky is clear and much solar radiation reaches the Earth's surface. The variation of sunshine with albedo depicts direct opposite relationship since the available sunshine hour in any location is the function of the prevailing atmospheric condition. Similar variation could be observed in Fig. $3 \mathrm{~b}$.

Solar radiation values started with $17.260 \mathrm{MJm}^{-1}$ day $^{-1}$ in January and steadily increases to its peak $\left(19.741 \mathrm{MJm}^{-1} \mathrm{day}^{-1}\right)$ in April. This value gradually decreases to its lowest value $\left(16.366 \mathrm{MJm}^{-1} \mathrm{day}^{-1}\right)$ in August and rises again to $18.658 \mathrm{MJm}^{-1} \mathrm{day}^{-1}$ in November, before finally decreases to $16.841 \mathrm{MJm}^{-1} \mathrm{day}^{-1}$ in December 
(Fig. 4a). The reflection coefficient varies in opposite direction to the solar radiation with its peak value $(0.575)$ during rainy season in August and lowest value (0.413) during dry season in November. The highest reflection co-efficient with the corresponding lowest solar radiation observed in August was probably due to the rain bearing clouds which pervaded the sky in the rainy season. It implies that more radiation was reflected back into space than received on the Earth's surface, hence, high brightness of the Earth's surface toward the space and low surface temperature of the Earth.

On the other hand, the high radiation observed in November and April during dry season was due to the fact that the sky was cloudless with little hamarttan dust, hence low albedo. It implies that the global solar radiation received on the Earth's surface was more than the reflected radiation lost into space. It also shows that the sky was relatively cloudless, albedo was relatively low and more radiation was available to the solar energy devices. The variation of annual mean global solar radiation with reflection co-efficient (Fig. 4b) also depict opposite variation as could be observed in Fig. 4a.

Annually, the highest $(0.60)$ and lowest (0.37) albedo were obtained in 2002 and 1995 respectively. This corresponds to the lowest $(0.40)$ and highest $(0.63)$ clearness index and also that of solar radiation as 14.21 and $22.69 \mathrm{MJm}^{-2} \mathrm{day}^{-1}$ respectively in the same years. This is in line with the work of Isikwue et al. (2014a) [13]. It is interesting to note from the foregoing that solar radiation and the albedo depict direct opposite relationship while sunshine hour varies directly with the solar radiation. Also, air temperature varies in the same pattern with the solar radiation. This is because air temperature is the reflection of both the duration and intensity of the solar radiation incident on a given location [14]; [15].

The results show that in the period under study, about $41 \%-57 \%$ of solar radiations in Kano are reflected into space during dry and rainy seasons respectively. This may be due to the cloudy nature of the atmosphere during rainy season and the influence of the harmattan dust from the Sahara Desert which affect the atmospheric condition over Kano. The albedo value obtained in this work ranged between 0.41 and 0.57 . These values are not too far from those obtained by [3] in Ilorin $\left(8^{0} 30^{\prime} \mathrm{N}, 4^{0} 34^{\prime} \mathrm{E}\right)$ but they are not too close due to latitudinal and physiological differences. Also, [4] in Maceio, Brazil $\left(9^{0} 40^{\prime} \mathrm{S}, 35^{\circ} 42^{\prime} \mathrm{W}\right)$ of coordinates almost similar to that of Kano obtained the albedo as 0.41 and 0.47 . [5], also obtained 0.5 and 0.7 as the albedo over the atmosphere of Makurdi $\left(7^{0} 41^{\prime} \mathrm{N}, 8^{0} 37^{\prime} \mathrm{E}\right)$.

\section{Conclusion}

$>$ The variation of albedo with clearness index, sunshine hour, surface temperature and solar radiation depict opposite relationship.

$>$ The albedos estimated from this research are 0.4 and 0.6 during dry season (November) and rainy season (August) respectively.

$>$ Annually, the maximum (0.60) and minimum (0.37) albedo were obtained in 2002 and 1995 respectively. Hence, further work to verify the relationship of albedo with other atmospheric parameters such as rainfall in these years is hereby suggested.

$>$ The atmospheric conditions for Kano for the period under review vary from being cloudy, heavily laden with harmattan dust, cloudless (clear) to dustless (clean). Hence, the prospect of solar energy technology by the Practitioner as alternative energy resources in the state is high.

\section{Acknowledgements} the data.

We appreciate the International Institute for Tropical Agriculture, Ibadan, Nigeria for providing us with

\section{References}

[1]. D. W. Madugu, F. W. Burari, and A. A. Bello. Experimental comparative study of the performances of constructed reliable model and standard pyranometer. Journal of Applied Sciences, 3 (2), 2010, 181-189.

[2]. W. F. Burari and S. A. and Sambo. Model for the prediction of global solar radiation for Bauchi using meteorological data. Renewable Energy. 9(1\&2), 2001, 30-33.

[3]. E. B. Babatunde, O. A. Falaiye, and C. C. Uhuegbu. Simulated reflection SW-radiation and its characteristic variation at Ilorin, Nigeria. Nigeria Journal of Physics, 175, 2005, 193-201.

[4]. J. L. De sonsa, M. Nicacio, and M. A. L. Monra. Solar Radiation Measurements in Maceio, Brazil,\| Renewable Energy. 30, 2005, 1203-1220.

[5]. M. O. Audu and B. C. Isikwue. Estimation of the Albedo of the Earth's Atmosphere at Makurdi, Nigeria. International Journal of Scientific \& Technology Research, 3 (4), 2014, 375-380. ISSN 2277-8616. www.ijstr.org.

[6]. W. Zhao, M. Tamura, and H. Takahashi. Atmospheric and Spectral Corrections for Estimating Surface Albedo from Satellite Data using 6S Code. Remote Sensing of Environment. 76, 2000, $202-212$.

[7]. B. Pinty and D. A. Ramond. A Method for the Estimation of Broadband Directional Surface Albedo from a Geostationary Satellite. Journal of Applied Meteorology, 26, 1987, 1709-1722.

[8]. A. Ibrahim. Efforts of the Shekarau admnistration in harnessing resources for social and economic development of Kano. A presentation to Course 28 of Command and Staff College Jaji, Research and Documentation Directorate 2, 2006.

[9]. E. B. Babatunde. Some solar radiation ratios and their interpretations with regards to radiation transfer in the atmosphere. Nig. J. of Pure and Appl.Sc. 4, 2003. 
[10]. J. A. Duffie and W. A. Beckman. Solar Engineering of Thermal Processes. John- Wiley and Sons, New York, 1991.

[11]. M. A. A. Fayadh and A. Ghazi. Estimation of global solar radiation in horizontal surfaces over Haditha, Samara and Beji, Iraq. Pacific J. of Sci. and Tech. 11, 1983, 73 -82.

[12]. P. I. Cooper. The Absorption of Solar Radiation in Solar Stills. Solar Energy, 12 (3), 1969, 313-317.

[13]. B. C. Isikwue, M. Akiishi and E. U. Utah. Investigation of radiation energy balance in some selected cities in Nigeria. IOSR Journal of Applied Physics (IOSR-JAP). 6(2), 2014a, 21-27. e-ISSN: 2278-4861. www.iosrjournals.org.

[14]. B. Isikwue, S. Dandy and M. Audu. Testing the performance of some empirical models for estimating global solar radiation over Makurdi, Nigeria. Journal of Natural Sciences Research, 3 (5), 2013b, 165-170.

[15]. M. Chegaar and F. Guechi. Estimation of global solar radiation using meteorological parameters. Rev. international D'Heliotechnique, 40, 2009, 18-23. 